\title{
Somogy megye ikerszelvényeseinek katalógusa (Diplopoda)
}

\author{
KORSÓS ZOLTÁN
}

\section{KORSós Z.: Catalogue of millipedes of Somogy county (Diplopoda)}

Abstract: Based on the literature data and research of the last decade, a synopsis of the millipede fauna of Somogy county, Southwestern Hungary is given. Altogether 40 species have been recorded, and further eight species can be expected. A catalogue is given with detailed comments on the distribution of each species.

\section{Bevezetés}

Somogy megye ikerszelvényeseinek (Diplopoda) kutatása történetét tekintve DADAY (1889) összefoglaló munkájával, „A magyarországi Myriopodák magánrajzá"-val kezdôdött. Bár Daday nem volt "myriapodológus“ és a csoport feldolgozását részben kényszerú feladatként kapta meg, táblázatos összeállítása a megyékben elóforduló Diplopodákról Somogyot tekintve egészen helytálló; a 7 felsorolt faj közül mindössze kettônek (Julus luscus, Julus varius) bizonytalan az érvényes taxonómiai helyzete. A többi öt, bár modern nevükön, de mind a mai napig érvényes tagjai Somogy megye ikerszelvényes-faunájának: Julus dicentrus (= Allajulus dicentrus), Julus unilineatus (= Megaphyllum unilineatum), Strongylosoma pallipes (=Strongylosoma stigmatosum), Polydesmus complanatus és Polydesmus denticulatus. A Julus dicentrus-t egyébként az a LATZEL (1884) írta le öt évvel korábban a tudomány számára, aki hazánk Myriapodáit tekintve az elsố monografikus munkát tette le az asztalra; igaz, könyvében nem tesz említést a leírás alapjául szolgáló példányok pontos lelóhelyéról, így csak feltételezhetjük, hogy már azok között voltak somogyiak.

DADAY (1896) a „magánrajz“ után nem sokkal még egy összefoglaló munkára szánta rá magát, ezúttal a „Magyar Birodalom állatvilága“ millenniumi sorozat számára készítette el a Myriaopoda-kötetet. Somogy szomszédságából, Nagykanizsáról csak egyetlen fajt jelez a Julus (= Allajulus) dicentrus-t. Baranyából, Abaligetről megemlíti a Polydesmus collaris-t, amely késóbb Somogy egyik leghíresebb, leglátványosabb ikerszelvénayese lesz (ld. színes fotó), de Daday ekkor még a megyéból származó példányait nem ismeri. A többi, korábbi munkájában említett fajok az „általánosan gyakori“ megjegyzést kapiák, külön előfordulási helymeghatározás nélkül.

A továbbiakban - néhány egészen esetleges munkától eltekintve - hosszú szünet következik, nemcsak Somogy megye ikerszelvényeseinek kutatásában, hanem a magyar myriapodológia tekintetében is egyaránt. Dudich Endre, Csiki Ernô, Chyzer Kornél, Szalay László és mások faunisztikai munkái közül Somogyhoz legközelebb csak SzABó (1932) közöl adatokat, nevezetesen a Tihanyi-félszigetról jelez összesen 7 Diplopoda-fajt. A Diplopodák néhány csoportját tárgyaló szinopszis jellegú dolgozatokban JermY (1942) a Glomerida 
rendról írva nem említ Somogyból egyetlen fajt sem; LoKSA (1954) pedig a Kárpát-medencei Polydesmus-fajok kapcsán mindössze a P. complanatus-t, collaris-t és denticulatus-t sorolja fel Somogyból.

Az elsô, Somogy egy részterületét részletesen tárgyaló faunisztikai munka a Diplopodákról szintén LoKSA (1981) nevéhez fúződik. A Barcsi Borókás állatvilágáa tárgyaló cikkben összesen 15 fajt ír le, köztük a Craspedosoma transsilvanicum egy új formáját (!): f. barcsicum. A késóbbiekben Korsós (1995, 1997, 1998) a Dráva-mellék kutatásába bekapcsolódva ezeket - három kivételével újra kimutatta, és további 2 l-gyel (!) gyarapította, köztük egy faunára új fajjal (Unciger transsilvanicus Baranyából, de Somogyból is várható), valamint nyolc olyannal, amelyekról csak nagyon kevés adat (egy-két példány és lelőhely) volt azidáig ismeretes Magyarországról. Bár határozókulcsot nem ad a régió ikerszelvényeseihez, a ritka fajok többségének ivarlábát jól azonosítható módon illusztrálta a három cikkben.

Bár tudományos közlemény nem született belóle, feltétlenül meg kell említeni a British Myriapod Group részvételével szervezett 1994-es gyứjtôexpedíciót, amelynek során az angol kutatócsoport hat tagja fáradhatatlan lelkesedéssel gyüjtötte végig Somogy megyét a Balatontól a Dráváig, és határozta meg késốbb a gyüjtött anyagot. Munkájukat nem kis siker koronázta: jópár új elốfordulási adat mellett egy újabb faunára új faj bukkant elő (Styrioiulus styricus, Zalából, Balatongyörökrớl)! Ezzel a hazai ikerszelvényes-fauna fajszáma 97-re, Somogy megyéé pedig (a várható fajokkal együtt) 48-ra emelkedett.

\section{A Somogy megyéből ismert fajok jegyzéke}

\section{POLYXENIDA}

Polyxenus lagurus (Linnaeus, 1758): KORSÓS (1998) („pamatos soklábú“).

\section{GLOMERIDA}

Glomeris hexasticha Brandt, 1833: LOKSA (1981), KORSÓS (1998) („gömbsoklábú“)

[Glomeris conspersa C. L. Koch, 1847: Eddig a Mecsekből és a Villányi-hegységból, a Jakabés a Nagyharsányi-hegyről említették (JERMY 1942). A szomszédos Szerbiában és Horvátországban is él, tehát elöfordulása Somogyban is várható (KORSÓS 1998).]

Trachysphaera gibbula (Latzel, 1884): Órtilosról került elő egyetlen példányban (KORSÓS 1998).

\section{POLYZONIIDA}

Polyzonium germanicum Brandt, 1837: Somogyból mindösze Szentborbásról került elô néhány példány (KORSÓS 1998) („szívó ezerlábú").

\begin{abstract}
CHORDEUMATIDA
Mastigona bosniensis (Verhoeff, 1897): A Dráva mellól mutattuk ki, de feltehetóen másfelé is gyakori (KORSÓS 1998).

Haasea hungarica (Verhoeff, 1928): Bélavárrról került elő ez a korábban az Abaligeti-barlang endemizmusának gondolt faj (KORSÓS 1998). Ezen kívül még a zalai Kovácsi-hegyen él (LOKSA 1961).

Craspedosoma rawlinsii Leach, 1814: Európa-szerte gyakori, változatos morfológiájú faj. Somogyból eddig csak Balatonfenyvesen fogtuk (KORSÓS 1998), de még nyilván sokfelé gyakori. LOKSA (1981) Barcsról leírta a Craspedosoma transsilvanicum (Verhoeff, 1897) $f$. barcsicum alakot, de a formakör változatosságát figyelembe véve ez is a C. rawlinsii-hez tartozónak tekinthetó (KORSÓS 1998).

Ochogona caroli (Rothenbühler, 1900): Csak LOKSA (1981) jelezte Barcsról, de nem sikerült újra gyújiteni (KORSÓS 1998).
\end{abstract}






1. ábra: Polydesmus collaris C. L. Koch, 1847 Fotó: Korsós Z.

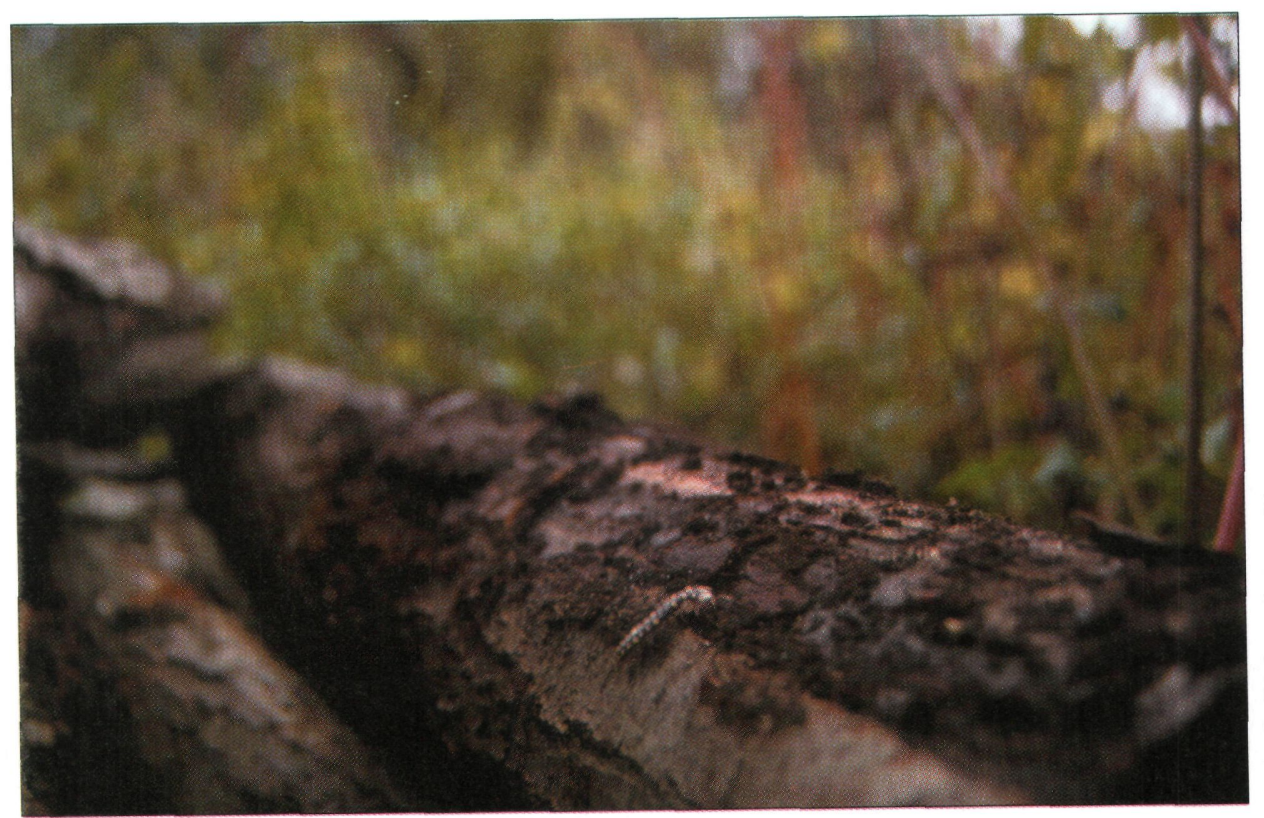

2. ábra: Sárganyakú ikerszelvényes (Polydesmus collaris) élóhelyén, ártéri puhafaligetben Fotó: Korsós Z. 


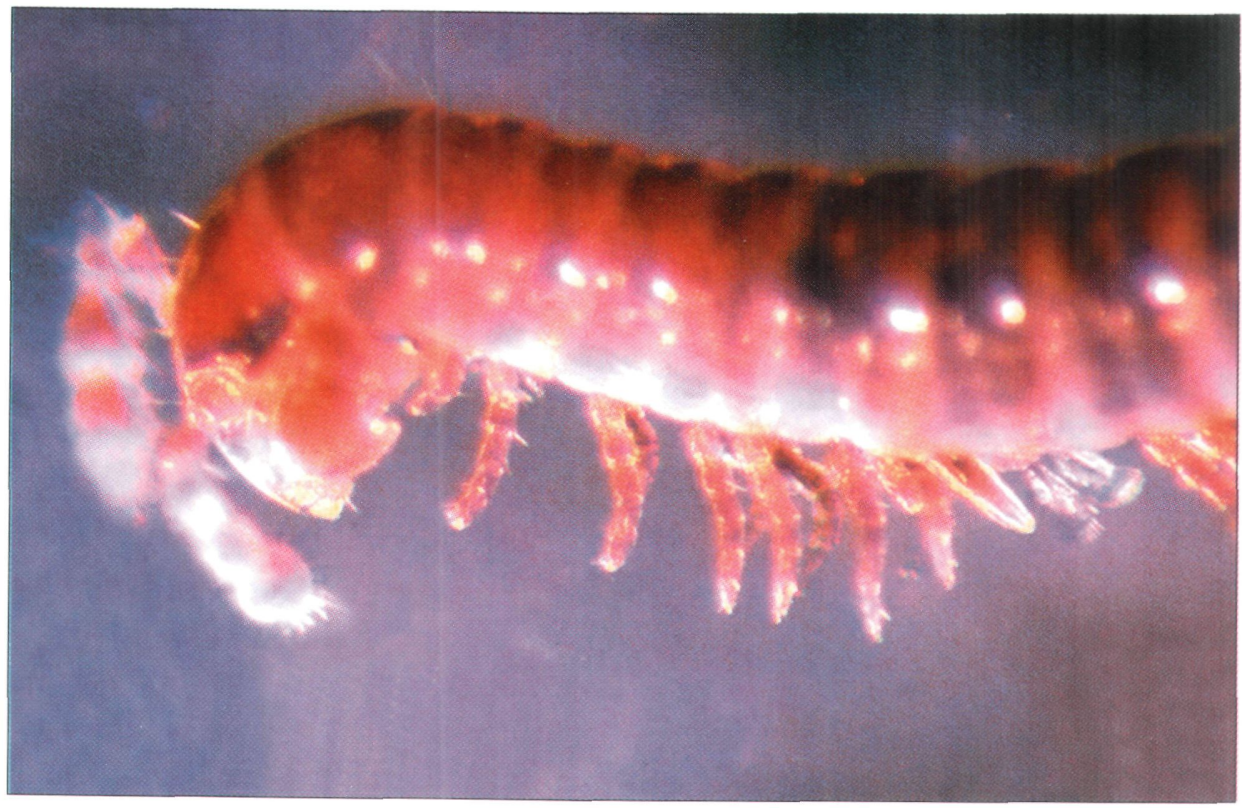

3. ábra: Nopoiulus kochii (Gervais, 1847) (hím) Fotó: Korsós Z.

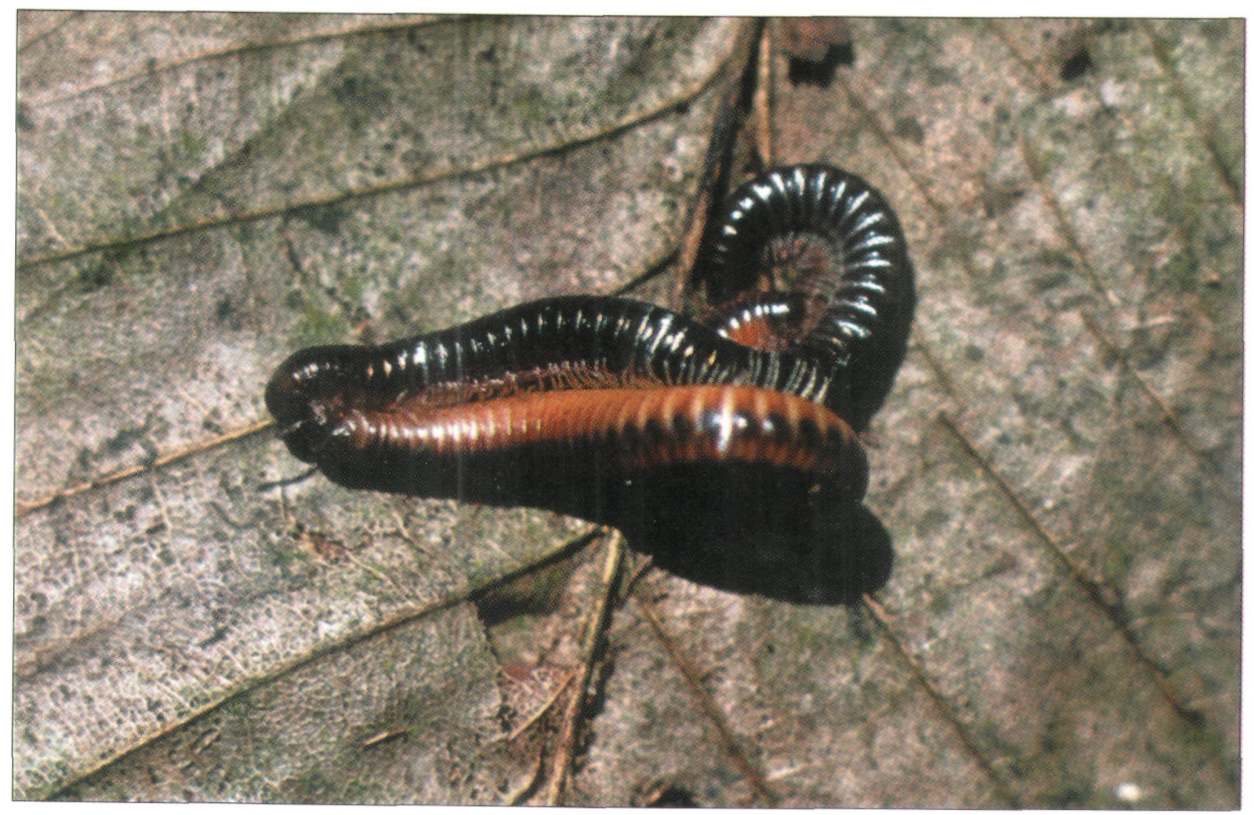

4. ábra: Megaphyllum projectum (Verhoeff, 1894) párzás közben (felül hím, lent nóstény) Fotó: Korsós Z. 
Melogona broelemanni (Verhoeff, 1897): Csak LOKSA (1981) jelezte 4 példányát ssp. gebhardti Loksa, 1962 alfajként Barcsról, de nem sikerült újra gyứjteni (KORSÓS 1998).

\section{JULIDA}

\section{Nemasomatidae}

Nemasoma varicorne C. L. Koch, 1847: Kéreglakó faj, Zákányról került elő (KORSÓS 1998), de másutt is várható.

\section{Blaniulidae}

Nopoiulus kochii (Gervais, 1847): Csak LOKSA (1981) jelezte Barcsról, de nem sikerült újra gyúiteni (KORSÓS 1998).

Boreoiulus tenuis (Bigler, 1913): Egyetlen adata: Szenyér (BMG 1994, det. H. Read). Magyarországról ezelôtt még nem jelezték, nyugat-európai, atlanti faunaelem.

Proteroiulus fuscus (Am Stein, 1857): Gyakori kéreglakó ikerszelvényes, Balatonfenyvesen (KORSÓS 1992) kúvül másfelé is várható.

Choneiulus palmatus (Nemec, 1895): Többnyire szinantróp, antropogén környezetben élô faj, Balatonfenyvesen (BMG 1994, det. H. Read) kívül a Balaton déli partján másfelé is várható.

[Cibiniulus phlepsii (Verhoeff, 1897): A szomszédos Tolna megyéből került elô (BMG 1994, det. H. Read), várható esetleg Somogyból is!]

\section{Julidae}

Allajulus dicentrus (Latzel, 1884): Hazánkban ritka faj, eddig csak Nagykanizsáról (DADAY 1896, LOKSA 1957) és Bélavárról került elö (KORSÓS 1998). Somogy meǵye ikerszelvényesfaunájának egyik különlegessége!

Allajulus groedensis (Attems, 1899): Egyetlen példányban került elố a Zákányi-erdőből (KORSÓS 1998). Különleges, ritka faj!

Brachyiulus bagnalli (Curtis, 1845): Gyakori, szinantróp elöfordulásra hajlamos ikerszelvényes (KORSÓS 1998).

Cylindroiulus abaligetanus Verhoeff, 1901: Somogy és Baranya ritka ikerszelvényese, Nagybajomról (LOKSA 1965) és Hosszúvízrôl, a Boronkai Tájvédelmi Körzetból ismert (KORSÓS \& READ 1994).

Cylindroiulus boleti (C. L. Koch, 1847): Korhadó fában mindenfelé elterjedt, talán a leggyakoribb magyarországi ikerszelvényes. Balatonfenyvesrốl mutattuk ki (KORSÓS 1992, KORSÓS 1998), de nyilván mindenütt elöfordul („farkatlan vaspondró“).
[Cylindroiulus horvathi (Verhoeff, 1897): A Balaton északi partjáról, Fejér és Baranya megyékból ismert (KORSÓS \& READ 1994), esetleg Somogyban is várható!]

Cylindroiulus latestriatus (Curtis, 1845): Szinantróp elófordulását mutattuk ki Balatonfenyvesen (KORSÓS 1992), a déli part üdüloókörzetében másutt is valószínû.

Cylindroiulus luridus (C. L. Koch, 1847): Gyakori faj, sokszor a C. boleti-vel együtt él (KORSÓS 1998).

Enantiulus nanus (Latzel, 1884): A Dráva mellett találtuk meg (KORSÓS 1998).

Julus terrestris Linnaeus, 1758: SZIRÁKI (1967) egy új, ma is érvényes alfaját, a J. t. balatonensis-t írta le Bélateleprôl.

Leptoiulus proximus (Nemec, 1896): Komolyabb lombhullató erdők jellegzetes faja mindenütt Magyarországon (KORSÓS 1998).

[Megaphyllum bosniense (Verhoeff, 1897) A ssp. cotinophilum Loksa, 1962 alfajt LOKSA (1968) a Keszthelyi-hegységból és Zalalövőről jelzi, esetleg Somogyban is várható. Mindamellett a Megaphyllum projectum csoport - ahova a bosniense is tartozik - taxonómiai revízióra vár.]

Megaphyllum projectum (Verhoeff, 1894): Tölgyesekben mindenütt gyakori, tömeges, társulásalkotó ikerszelvényesfaj („endei vaspondró“).

[Megaphyllum transsylvanicum (Verhoeff, 1897) ssp. transdanubicum Loksa, 1962: A Villányi-hegységbool és a Mecsekbool írta le LOKSA, esetleg Somogyból is várható! A revízió itt is szükséges.]

Megaphyllum unilineatum (C. L. Koch, 1838): Környezetét tekinve igénytelen, szárazságtûrô faj, az emberi zavarást, mezôgazdasági behatást is jól elviseli („vonalas vaspondró“).

Ommatoiulus sabulosus (Linnaeus, 1758): Gyakori, szárazságtürő faj (,homoki vaspondró").

Ophyiulus pilosus (Newport, 1842): Gyakori, Nyugat-Európában szinantróp hajlamú faj.

Styrioiulus pelidnus (Latzel, 1884): Csak a Kôszegi-hegységből és a Dráva mellől (Bélavár, KORSÓS 1998) ismert.

[Styrioiulus styricus (Verhoeff, 1896): Balatongyörökrởl került elő (BMG 1994), esetleg Somogy megyéból is várható!]

Unciger foetidus (C. L. Koch, 1838): Gyakori faj (,horgas vaspondró").

[Unciger transsilvanicus Verhoeff, 1899: Baranyából került elổ egy példányban faunára újként (KORSÓS 1998), esetleg Somogyból is várható!]

Xestoiulus imbectitus (Latzel, 1884): A Dráva-mellól vált ismertté (KORSÓS 1998). 
Xestoiulus laeticollis (Porat, 1889) ssp. dudichi (Verhoeff, 1927): Ez az alfaj korábban csak Bátorligetról volt ismert (Korsós 1991), majd Somogy megye égerlápos erdeiból is elókerült (KORSÓS 1998). LOKSA (1965) Nagybajomból leírta a ssp. evae alfajt, amelynek a típuspéldányát eddig még nem sikerült azonosítani (esetleg csak szinonim).

\section{POLYDESMIDA}

\section{Paradoxosomatidae}

Oxidus gracilis (C. L. Koch, 1847): Délkeletázsiai eredetú, kozmopolita, szinantróp faj (KORSÓS 1998).

Strongylosoma stigmatosum (Eichwald, 1830): Közönséges erdei faj („sárgalábú ikerszelvényes").

Stosatea italica (Latzel, 1886): Balatonfenyvesen, szinantróp környezetből került eló egy példány (BMG 1994, det. H. Read). Eddig csak egyetlen adata volt ismert Szeged mellól (KORSÓS 1998).

\section{Polydesmidae}

[Brachydesmus attemsii Verhoeff, 1895: Baranya megyéből, a Vajszló melletti tölgyesból került elố (KORSÓS 1998), talán Somogyból is várható.]

Brachydesmus superus Latzel, 1884: Egyetlen adata: Hosszúvíz (BMG 1994, det. H. Read).

Polydesmus collaris C. L. Koch, 1847: Jellegzetes délnyugat-magyarországi faj, eddig csak Zala, Somogy és Baranya megyékből ismeretes (ld. fotó) (KORSÓS 1998). Somogy megye ikerszelvényes-nevezetessége!

Polydesmus complanatus (Linnaeus, 1761): Gyakori kéreglakó Diplopoda („karimás ikerszelvényes“).

Polydesmus denticulatus C. L. Koch, 1847: Nedves erdók gyakori faja.

Polydesmus edentulus C. L. Koch, 1847: A Dráva-kutatás (Korsós 1995, 1997, 1998) Barcs, Bélavár és Zákány mellôl mutatta ki az addig csak a keszthelyi Kovácsi-hegyrôl ismeretes fajt; LOKSA (1958) a Zalából, Szakonyfaluból írta le a ssp. bidentatus $\mathrm{f}$. hungarica alakot, amely valószínúleg csak egyedi változatosságot jelképez, taxonómiai jelentőség nélkül.

\section{1. táblázat: Somogy megye ikerszelvényes-fajszámai összefoglalóan, rendek és családok szerint megosztva}

\begin{tabular}{|l|c|}
\hline Rend, Család & Fajszám \\
\hline POLYXENIDA & 1 \\
\hline GLOMERIDA & \\
Glomeridae & 1 \\
Trachysphaeridae & 1 \\
\hline POLYZONIIDA & 1 \\
\hline CHORDEUMATIDA & 5 \\
\hline JULIDA & \\
Nemasomatidae & 1 \\
Blaniulidae & 4 \\
Julidae & 18 \\
\hline POLYDESMIDA & \\
Paradoxosomatidae & 3 \\
Polydesmidae & 5 \\
\hline Összesen: & 40 \\
\hline
\end{tabular}


A Somogy megyében élő ikerszelvényes fajok száma (40) a magyarországi összfajszám (97) 41,2 \%-a, plusz 8 további faj előfordulása várható. Ez igen magas, csaknem 50 \%-os (48/97) arány! De nemcsak ez a magas fajszám mutatja a megye Diplopodáinak gazdagságát; a fauna összetétele is rendkívül figyelemre méltó: mediterrán, atlanti és pontusi elemek keverednek itt, számos olyan fajjal, amelyek itt érik el elterjedésük északi, keleti vagy nyugati határát. Ha tekintetbe vesszük mindazt, hogy ez az állatcsoport - érdemtelenül - milyen kevés figyelmet kap a zoológusoktól, hogy milyen tekintélyes anyag van még feldolgozatlanul a múzeumi gyújteményekben, és hogy egyes eldugott területek mi mindent rejthetnek, bátran állíthatjuk, hogy az ikerszelvényeseket tekintve Magyarországnak talán a legértékesebb, legtöbb felfedezést sejtető vidéke Somogy megye!

\section{Köszönetnyilvánítás}

A kutatást a T26172 sz. OTKA - pályázat támogatta.

\section{Irodalom}

BMG (1994): Korsós, Z., Read, H. J., Barber, A. D., Gregory, S. J., HornunG, E., Jones, R. E., KIME, R. D. \& LEWIS, J. G. E: (in prep.): Report on a collecting trip of the British Myriapod Group to Hungary in 1994. - Manuscript

DADAY, J. ( 1889 ): A magyarországi Myriopodák magánrajza. - Kir. M. Természettud. Társ., Budapest, $126+$ I-III pp.

DADAY, J. (1896): Classis Myriopoda. - In: A Magyar Birodalom Állatvilága, Fauna Regni Hungariae, Term. Tud. Társulat, Budapest, 11 pp.

JERMY, T. (1942): Rendszertani tanulmány a magyarországi plesioceratákról (Diplopoda). - Mat. Term.tud. Közlem., 39: 1-82.

Korsós, Z. \& ENGHOFF, H. (1990): The Cylindroiulus truncorum-group (Diplopoda: Julidae). Ent. scand.,21: 345-360.

Korsós, Z. (1992): Millipedes from anthropogenic habitats in Hungary (Diplopoda). - Ber. natur.-med. Ver. Innsbruck, Suppl., 10: 237-241.

KORSÓS, Z. (1994): Checklist, preliminary distribution maps, and bibliography of millipedes in Hungary (Diplopoda). - Miscnea zool. hung., 9: 29-82.

Korsós, Z. (1995): Néhány adat a Dráva-mellék ikerszelvényes (Diplopoda) faunájához. Elözetes közlemény. - Dunántúli Dolg. Term. tud. Sorozat, Pécs, 8: 31-36.

KoRSós, Z. (1997): The millipede fauna of the Dráva Region, southern Hungary (Diplopoda). Ent. scand. Suppl., 51:219-224.

Korsós, Z. (1997[1998]): Az ikerszelvényesek (Diplopoda) faunisztikai és taxonómiai kutatásának helyzete és irányai Magyarországon. - Folia hist. nat. Mus. Matraensis, 22: 85-98.

Korsós, Z. (1998): A Dráva mente ikerszelvényes (Diplopoda) faunája. - Dunántúli Dolg. Term.tud. Sorozat, Pécs, 9: 81-96.

Korsós, Z. \& READ, H. J. (1994): Revision of the horvathi group and description of a new species of Cylindroiulus (Diplopoda: Julidae). - J. nat. Hist., 28: 841-852.

LATZel, R. (1884): Die Myriopoden der österreichisch-ungarischen Monarchie, II. Die Symphylen, Pauropoden und Diplopoden. - Alfred Hölder, Wien, pp. $228+414$.

LOKSA, I. (1954): Die Polydesmus-Arten des Faunengebietes des Karpatenbeckens. - Annls hist.nat. Mus. natn. hung., s. n., 5: 215-224. 
LOKSA, I. (1957): Ergebnisse der Überprüfung einer Diplopodensammlung von J. Daday. - Ann. Univ. Sci. Budapest, 1: 189-195.

LOKSA, I. (1958): Eine neue Form von Polydesmus (Acanthotarsius) edentulus bidentatus Verh. aus Ungarn, und Beiträge zur Mikroskulptur der Polydesmiden. - Opusc. zool. Budapest, 2: 49-54.

LOKSA, I. (1961b): A Kovácsi-hegy ízeltlábúiról (Die Arthropoden des Kovácsi-Berges). - Állatt. Közlem., 46: 65-80. (in Hungarian, with German summary)

LOKSA, I. (1962): Einige neue und wenig bekannte Diplopoden aus Ungarn. - Ann. Univ. Sci. Budapest, 5: 157-170.

LOKSA, I. (1965): Zwei interessante Diplopoden-Funde aus Transdanubien (Ungarn). - Opusc. zool. Budapest, 5: 217-221.

LOKSA, I. (1981): A Barcsi Borókás ikerszelvényes (Diplopoda) és százlábú (Chilopoda) faunája. - Dunántúli Dolg. Természettud. Sor. Pécs, 2: 45-52.

SZIRÁKI, GY. (1966): Magyarország nőstény Diplopodáinak határozója. - Egyetemi doktori diszszertáció, ELTE, Budapest, 52 pp.

SZIRÁKI, GY, (1967): Zwei neue Diplopoden-Unterarten aus Ungarn. - Opusc. zool. Budapest, 7: 259-261.

\section{Catalogue of millepodes of Somogy county (Diplopoda)}

\section{ZOLTÁN KORSÓS}

Similarly to whole Hungary, there are relatively few records of millipedes (Diplopoda) with special regards to the fauna of Somogy county, South-western Hungary. In addition to the data extracted from previous general faunistical works (LATZel 1884, DADAY 1889, Daday 1896, Jermy 1942, SziráKI 1966), special reports about the millipedes of some parts of the county (Barcs: LOKSA 1981, Drava Region: KORSÓS 1995, 1997, 1998) are summarized here, yielding a total number of 40 species. This represents a relatively high ratio $(41.2 \%)$ of the complete Hungarian Diplopoda fauna, reaching almost $50 \%$ with eight more species expected from the neighbouring counties! It is not only the high number of species which illustrates the richness of the fauna of Somogy county ; the composition of species is also remarkable, with occurrences of Mediterranean, Atlantic and Continental faunal elements. Some of the species reach here the western-, northern- or easternmost edge of their distribution. Interesting species are: Haasea hungarica, Allajulus dicentrus, Allajulus groedensis, Cylindroiulus abaligetanus, Styrioiulus pelidnus, Xestoiulus imbecillus, Xestoiulus laeticollis, Polydesmus collaris, and Polydesmus edentulus. If we consider how much more unidentified material are housed in local natural history collections, and that some remote parts of the county are still unexplored as to their soil fauna, it is maybe not an exaggeration that from the myriapodological point of view Somogy county is perhaps the most interesting and promising region of Hungary!

Author's address:

Dr. Zoltán Korsós

Department of Zoology

Hungarian Natural History Museum

Baross u. 13,

H-1088 Budapest

HUNGARY 